\title{
Design and Implementation of Solar Panel MPPT with Inverter and Battery Towards Load Side
}

\author{
Prof. Najma Siddiqui*, Mohammad Anwar, Junaid Akhtar, Ehtesham Asif, Mohammad Rehan, Tafim Khan \\ Department of Electrical Engineering, Anjuman College of Engineering, and Technology, Sadar, Maharashtra, \\ India
}

Article Info

Volume 8, Issue 3

Page Number : 943-951

Publication Issue

May-June-2021

\section{Article History}

Accepted : 18 June 2021

Published : 26 June 2021

\section{ABSTRACT}

In India the requirement and availability of energy for power supply is 11,14408 million units and 10,90850 million units for 2015-16 and we also know that the human activities is mostly dependent on electrical power supply. The above fact clearly shows that the supply is not meeting the demand. As a result frequent power-cut is done and interrupted power supply is provided. The alternative for this problem is to switch towards renewable energy resources. Four different sources i.e. mains, generator, solar and inverter are used to provide uninterrupted power supply. Using the solar energy as one of the power source provides the solution for low energy resources since it is a non-renewable source of energy. The second objective of work is to provide automation which make the work faster, reliable, efficient, and reduce human efforts. Microcontroller (PIC/AT89C51) is used to provide automation in the switching between four different sources. The automation system used for switching requires separate source to provide an output signal which will operate the four different relays connected to sources respectively

Keywords - Solar, Inverter, Relay, MPPT, Battery.

\section{INTRODUCTION}

An uninterruptible power supply, commonly called a UPS is a device that has the ability to convert and control direct current (DC) energy to alternating current (AC) energy. It uses a conventional battery of $12 \mathrm{~V}$ rating as the input source and by the action of the inverter circuitry, it produces an alternating voltage which is sent to the load. This particular UPS is designed for a small scale load like a personal computer and hence only a basic power rate is generated by the UPS. Many believe that because an inverter is operating from a nominal $12 \mathrm{~V}$ battery and it cannot deliver as much output as a normal mains power outlet, its relatively safe. This is not usually true. Even a low power inverter rated at a mere 60 watts has an output which is potentially fatal if 2 you become its load. Such an inverter can have a typical output of $350 \mathrm{~mA}$ at $230 \mathrm{~V}$. This is above ten (10) times the current level connected to cause fatal 
fibrillation and stop your heart. Generally, uninterrupted power supply (UPS) can be grouped by source or method of functionality. (1) By Source: Here we have a voltage source (DC) for its operation or a current source (DC). The current source however is used for very high power consumption devices hence this design is a voltage source UPS. (2) By Functionality: Amongst others here is the single tracked and dual-tract UPS. The single-tract UPS feeds the load continuously from the rectified DC supply directly. This type of UPS is disadvantaged because a fault in the rectification stage leads to a complete system failure. The dual tract acts like the single tract but it has a bypass that sources from the mains supply. Hence the battery is used only as backup and does not run all the time unlike the single track. This design is a dual track methodology. For an ideal UPS, basic functionality is needed (1) Being a backup utility, a UPS must ensure that there is no break in the power supply at any point in time unless major faults like fuse cuts are experienced. (2) An ideal UPS must provide the battery with an adequate charge so as to maintain the optimum conversion rate to AC when needed. (3) It must also ensure overcharge protection to prevent the battery from being damaged. (4) All forms of surges and undesired waveforms that may emanate from inverted source voltage are to be filtered and well suited to the output level. (5) Must be sensitive to maintain stability when the battery safe voltage is being exceeded. (6) It must also provide an overload protection for the entire unit. Many embedded devices provide a rich GUI-based user experience; use file systems, multiprocessing, and multi-threading; and include networking. An operating system (OS) can provide these features to support the rapid development of application programs $[1,2]$. In charging a battery of the personal computer (PC), a cheap, unattended, unregulated charger can destroy a battery by overcharging it.

\section{LITERATURE REVIEW}

1.Automatic Control System of Power Supply of Active Consumers978-1-5090-5648-417\$31.00 (C2017 IEEE Kulikov A.L., Sharygin M.V. The paper proposes an architecture for such a control system based on typical intellectual electronic devices (IED) and connection channels in accordance with IEC 61850. It proposes a principle for determining active consumers based on search for optimal variants of short-time partial customers disconnection (restrictions). Availability of production reserves and various types of customer excess potentially enable a short time disconnection without process no interruption or production suspension.

2. Power Supply Control from Different Sources International Journal of Scientific \& Engineering Research, Volume 7, Issue 1, January-2016 484 ISSN 2229-5518 Mr.Shahaji Dudhate The main purpose of this paper is to provide continuous power supply to a load, by selecting the supply from any of the four sources namely solar, inverter, main and generator automatically in case if one the source is absent. The need of electricity is increasing day by day and the frequent power cuts of electricity are causing many problems in different areas like banks, colleges/schools, hospitals, houses and industries

3. Design and Implementation of an Automatic Power Supply From Four Different Source Using Microcontroller Indo-Iranian Journal of Scientific Research (IIJSR) Volume 1, Issue 1, Pages 123-131, October-December 2017 Amanyire Ronald1 . This paper is designed to automatically supply continuous power to a load through one of the four sources of supply that are: solar, mains, thermal, and wind when any one of them is unavailable. The four switches represent the four causes. The switches are connected to an 8051 microcontroller of which they provide input signals. Whenever a switch is pressed, it shows the absence of that particular reference. A relay driver is used that receives microcontroller generated output and switches that specific relay to provide continuous 
power supply. A lamp or bulb was used as a load for demonstration purpose which draws power from main.

4. A Survey on Uninterrupted Power Supply Using Four Different Sources Volume 8, Issue III, March/2018 International Journal of Advanced in Management, Technology and Engineering Sciences Adarsh Kumar Pande This paper deals with the automation of switching between different sources so as to get uninterrupted power supply and that to at low economical cost. Multiple sources increase the reliability of the system and the system is more robust to power failures and faults. The paper implements micro controller based circuit with relays to facilitate automatic prudent shift of power supply from the various available sources.

5. Automatic Power Supply Switching Control System between Three Different Sources D.V.Sai Subhanand International Journal for Research in Applied Science \& Engineering Technology (IJRASET) ISSN: 23219653; IC Value: 45.98; SJ Impact Factor:6.887 Volume 5 Issue VII, July 2017 The main purpose of this project is to provide continuous power supply to a load, by selecting the supply from any of the four sources namely solar, inverter, mains and generator automatically in case if one the source is absent

6. Design and Implementation of an Automatic Power Supply from Four Different Source Using Microcontroller

Abdurrahman Shuaibu January 2018 https://www.researchgate.net/publication This paper is designed to automatically supply continuous power to a load through one of the four sources of supply that are: solar, mains, thermal, and wind when any one of them is unavailable. The four switches represent the four causes.

7. Location methods of oscillation sources in power systems: a survey Bin WANG Kai SUN Journal of Modern Power Systems and Clean Energy Mar 2017 The deployment of a synchrophasor-based wide-area measurement system (WAMS) in a power grid largely improves the observability of power system dynamics and the operators real-time situational awareness for potential stability issues. The WAMS in many power grids has successfully captured system oscillation events

8. Multilevel Inverters: A Survey of Topologies, Controls, and Applications IEEE TRANSACTIONS ON INDUSTRIAL ELECTRONICS, VOL. 49, NO. 4, AUGUST 2002José Rodríguez The need of an active front end at the input side for those inverters supplying regenerative loads is also discussed, and the circuit topology options are also presented. Finally, the peripherally developing areas such as high-voltage high-power devices and optical sensors and other opportunities for future development are addressed.

9. Methods for maintaining the continuity of power supply International Conference on Applied Sciences (ICAS2017) This paper presents alternative solutions to ensure power supply of critical consumer, such hospitals. In a hospital it is extremely important to have a power supply without any interruption.

10. Automatic power supply controller by four different sources 2017 ICITSEM Smt. Thilagavathy The main objective of this paper is to provide uninterrupted power supply to a load, by selecting the supply from any source out of four such as mains, inverter, solar and generator automatically in the absence of any of the source.

\section{METHODOLOGY}

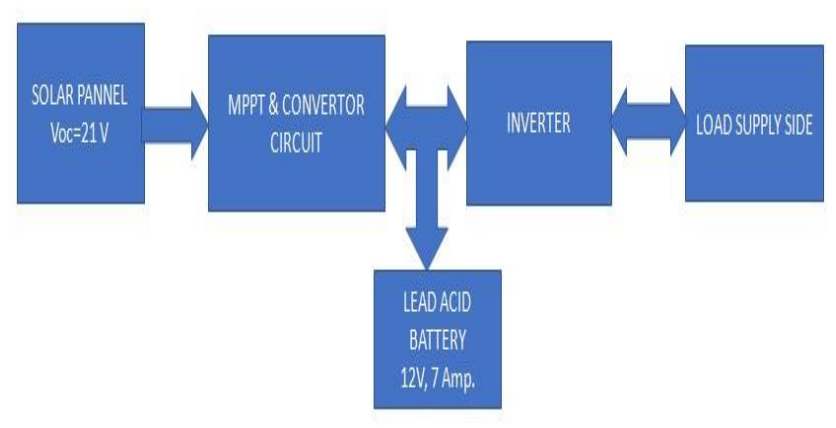

Figure 3.1 Block Diagram 


\section{A) Working}

This uninterrupted power supply control system works on the principle of auto selection for switch over the load to other available source without interruption or switch off the load. This work uses 4 different sources of supply which drive the load and provide uninterrupted power supply. All the four sources are connected parallel to each other as shown in the block diagram. The sequence of power sources is mains, solar, inverter and generator respectively i.e. highest priority is given to mains and least priority to generator.

At normal condition i.e. when mains supply is present, relay connected to mains sense the output from the mains and load is driven by mains supply. All other sources which are connected in parallel are open at this time. In case mains supply is cut off, power is automatically drawn from second source i.e. solar. If solar supply is absent the microcontroller will switched to inverter supply. If inverter supply also fails, the supply will automatically shift to generator. One of the other possible case is when power switches from one source to another source, say solar supply fails and supply shifts to inverter and at the same time if mains supply comes back then the supply will automatically switched to mains supply instead of switching to inverter because mains supply has been given the highest priority. The selection process of sources is done automatically using microcontroller. In this system microcontroller is very essential component and always keep sensing the available sources. When any source is switched off through the selection keys then the microcontroller shifted the load to the other supply source by giving the signal to the relay driver IC then the relay driver IC switched on the appropriate load relay. Load relays used in this work are connected in parallel with load and four sources of supplies are also connected in parallel with these load relays. These load relays consist of normally open and close contacts and are operated through the relay driver IC. We have checked this system by connecting the lamp at output side as a load. When any interruption takes place in the power supply lamp will not blink during the shifting of sources. Otherwise there will be blinking during the shifted time of the sources i.e. there is interruption in supplying the power at output side of the work.

Microcontroller PIC 16F877A: In this auto power supply control system, the PIC 18F877A microcontroller is used for the auto selection of the available source.

It shifted the load to the other power supply source automatically without any interruption. It is programmed in c language with help of micro c software and is powered up with $5 \mathrm{~V}$ dc voltages. It is interfaced with LCD display and relay driver IC. Relay Driver: In this auto power supply control system, the relay driver ULN2003 is used for driving the load relays. This relay receives the signal from microcontroller for shifting the load on another supply source. It is powered up with $5 \mathrm{~V}$ dc and interfaced with microcontroller.

Transformer: The transformer is used for connecting this system directly to $220 \mathrm{~V}$ AC. It steps down $220 \mathrm{~V}$ into $12 \mathrm{~V}$.

Voltage Regulator: The voltage regulator is used for regulating $12 \mathrm{~V}$ DC into $5 \mathrm{~V}$ DC voltages for supplying the power to the LED, microcontroller and other components. IC LM 7805 voltage regulator is used for regulating voltages.

LCD Display: LCD display is used for displaying the source of supply on which the whole system is working.

FILTERS: Capacitive filters are used in this work. It removes the ripples from output of the rectifier. The DC output received from this filter is constant until the mains voltage and load is maintained constant but if either one of the quantities is vary; the DC output received at this point changes. To overcome this 
drawback a regulator is applied at the output stage of the filter.

RECTIFIER: In this work bridge rectifier is used due to its merits like full wave rectification and high stability. For a single half of the cycle only two diodes will be in forward bias condition.

\section{B) Problem Formulation}

To eliminate the problem of power outages and data loss by maintaining power to the critical loads. To try and reduce or eliminate the whole process of double conversion method of accepting $\mathrm{AC}$, rectifying to DC for passing through the rechargeable battery, then inverting back to $\mathrm{AC}$ for powering equipment.

Thus the objectives from the problem statement are:

1. To investigate the viability of and analyze relative power conception of a system to supply DC power directly to selected electronic devices commonly connected to the main supply for operation. 2. To protect the critical loads from power interruptions.

3. To analyze a complete circuit design. 4. To make comparison between simulation \& experimental result.

The main reason behind to selects this work is there are lot of industries and domestic appliances which work on high voltage supply and are high costly. And some electrical devices need regular or uninterrupted or continuous power supply to work well for longer life span. Many electrical system are highly sensitive which can be affected by a minute interruption in the power supply line. In the power supply system there are many chances of interruption to take places at any times like power fail/cut off, faults etc. To avoid such types of problems these project system are best which take power supply via four different sources and alternate between them using microcontroller. The merit of this work is that they are reliable and economical.

\section{HARDWARE DESCRIPTION}

In our project, we utilized best and economical devices with exact and precise readings to make our project smart and intelligent. The Hardware components we use are:

HARDWARE:

- Atmega32 8bit Microcontroller

- Relay Driver IC

- Relays

- Crystal

- Diodes

- Load series for output

- Connectors multilevel

- Crocodile clips with auxillary

- SG3254 IC

- Solar Panel Voc $21 \mathrm{v}$

- PCB

- TIP41 High Power NPN Transistor Resistors (4 ohm,100k, 1k, 4.7k, 10k, 100k)

- Capacitors (100uf, 0.1uf, 0.001uf)

- Battery lead acid 12v 7 amp (depends)

- Heat sink

- Current IC \& Voltage IC

- Bud iron panel \& Bud wooden panel

- Solar and battery

- Convertor

- Screw

- Connecting Wires

Atmega32 8bit microcontroller:- It is the control unit of the whole circuit. Which gives the command signals depending on a $\mathrm{C}$ program which been installed in it already.

Background:- In our days, there have been so advancement in the field of Electronics and many cutting edge technologies are being developed every day, but still 8 bit microcontrollers have its own role in the digital electronics market dominated by $16-32$ \& 64 bit digital devices. Although powerful microcontrollers with higher processing capabilities exist in the market, 8 bit microcontrollers still hold its 
value because of their easy-to-understand- operation, very much high popularity, ability to simplify a digital circuit, low cost compared to features offered, addition of many new features in a single IC and interest of manufacturers and consumers.

Today microcontrollers are much different from what it were in the initial stage, and the number of manufacturers are much more in count than it was a decade or two ago. At present some of the major manufacturers are Microchip (publication PIC microcontrollers), Atmel (publication AVR microcontrollers). Our interest is upon ATmega32. It belongs to Atmel's AVR series micro controller family. Let's see the features.

PIN count:- Atmega32 has got 40 pins. Two for Power (pin no.10: $+5 \mathrm{v}$, pin no. 11: ground), two for oscillator (pin 12, 13), one for reset (pin 9), three for providing necessary power and reference voltage to its internal ADC, and $32(4 \times 8) \mathrm{I} / \mathrm{O}$ pins .

About I/O pins:- ATmega32 is capable of handling analogue inputs. Port $A$ can be used as either DIGITAL I/O Lines or each individual pin can be used as a single input channel to the internal ADC of ATmega32, plus a pair of pins AREF, AVCC \& GND (refer to ATmega32 data sheet) together can make an ADC channel. No pins can perform and serve for two purposes (for an example: Port A pins cannot work as a Digital I/O pin while the Internal ADC is activated) at the same time. It's the programmers are responsibility to resolve the conflict in the circuitry and the program. Programmers are advised to have a look

To the priority tables and the internal configuration from the datasheet..

Digital I/O pins:- ATmega32 has 32 pins (4portsx8pins) configurable as Digital I/O pins.

Timers:- 3Inbuilt timer/counters, two 8 bit (timer 0 , timer 2) and one16 bit (timer1).

ADC:- It has one successive approximation type ADC in which total 8 single channels are selectable. They can also be used as 7 (for TQFP packages) or 2 (for
DIP packages) differential channels. Reference is selectable, either an external reference can be used or the internal $2.56 \mathrm{~V}$ reference can be brought into action. There external reference can be connected to the AREF pin.

Communication Options:- ATmega32 has three data transfer modules embedded in it. They are

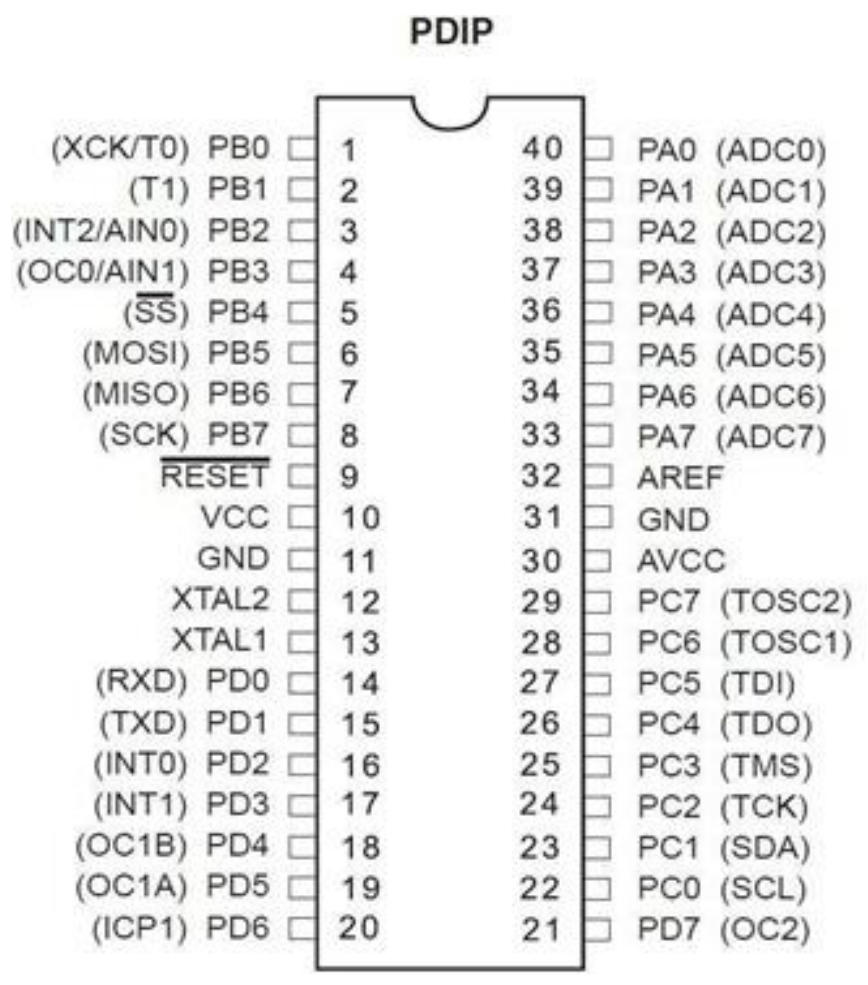

Figure 4.1 shows Atmega32 pin diagram

Analog comparator:- On-chip analog comparator is available. An interrupt is assigned for different comparison result obtained from the inputs.

External Interrupt:- 3External interrupt is accepted. Interrupt sense is configurable.

Memory:- It has 32Kbytes of In-System Selfprogrammable Flash program memory, 1024 Bytes EEPROM, 2Kbytes Internal SRAM. Write/Erase Cycles: 10,000 flash / 100,000 EEPROM.

Clock:- It can run at a frequency from 1 to $16 \mathrm{MHZ}$. Frequency can be obtained from external Quartz Crystal, Ceramic crystal or an R-C network. Internal calibrated RC oscillator can also be used. 
More Features:- Up to 16 MIPS throughput at 16 $\mathrm{MHz}$.Most of the instruction executes in a single cycle. Two cycle on-chip multiplication. $32 \times 8$ General Purpose Working Registers

Programming:- Atmega32 can be programmed either by In-System Programming via Serial peripheral interface or by Parallel programming. Programming via JTAG interface is also possible. Programmer must ensure that SPI programming and JTAG are not being disabled using fuse bits; if the programming is supposed to be done using SPI or JTA..

\section{Relay :-}

It is an electromagnetic switch.

Used to control the electrical devices.

Copper core magnetic flux plays an important role here.

A relay is an electrically operated switch. Current flowing through the coil of the relay creates a magnetic field which attracts a lever and changes the switch contacts. The coil current can be on or off so relays have two switch positions and they are double throw (changeover) switches.

The relay's switch connections are usually labeled COM (POLE), NC and NO, COM/POLE= Common, $\mathrm{NC}$ and $\mathrm{NO}$ always connect to the moving part of the switch. $\mathrm{NC}=$ Normally Closed, COM/POLE is connected to this when the relay coil is not magnetized. $\mathrm{NO}=$ Normally Open, $\mathrm{COM} / \mathrm{POLE}$ is connected to this when the relay coil is magnetized and vice versa. A relay shown in the picture is an electromagnetic or mechanical relay.
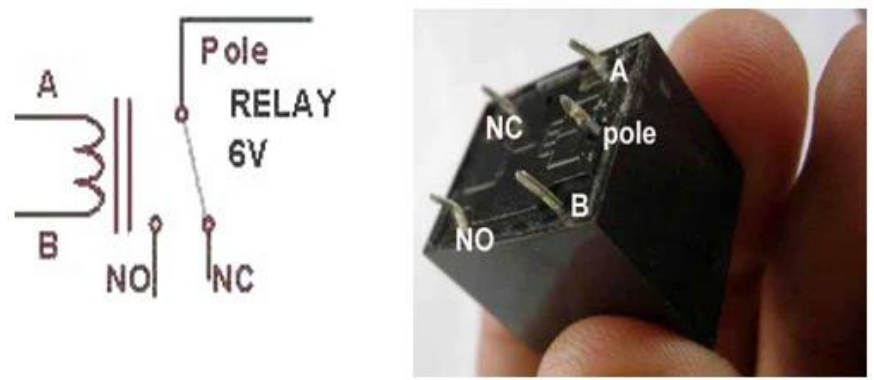

Figure 4.2 shows the actual relay and the relay circuit

\section{Relay derive IC:-}

The ULN functions as an inverter.

If the logic at input $1 \mathrm{~B}$ is high then the output at its corresponding pin $1 \mathrm{C}$ will be low.

The ULN2003A is an array of seven NPN Darlington transistors capable of $500 \mathrm{~m}$.A, $50 \mathrm{~V}$ output. It features common-cathode fly back diodes for switching inductive loads. It can come in PDIP, SOIC, SOP or TSSOP packaging.

\section{LOGIC DIAGRAM}

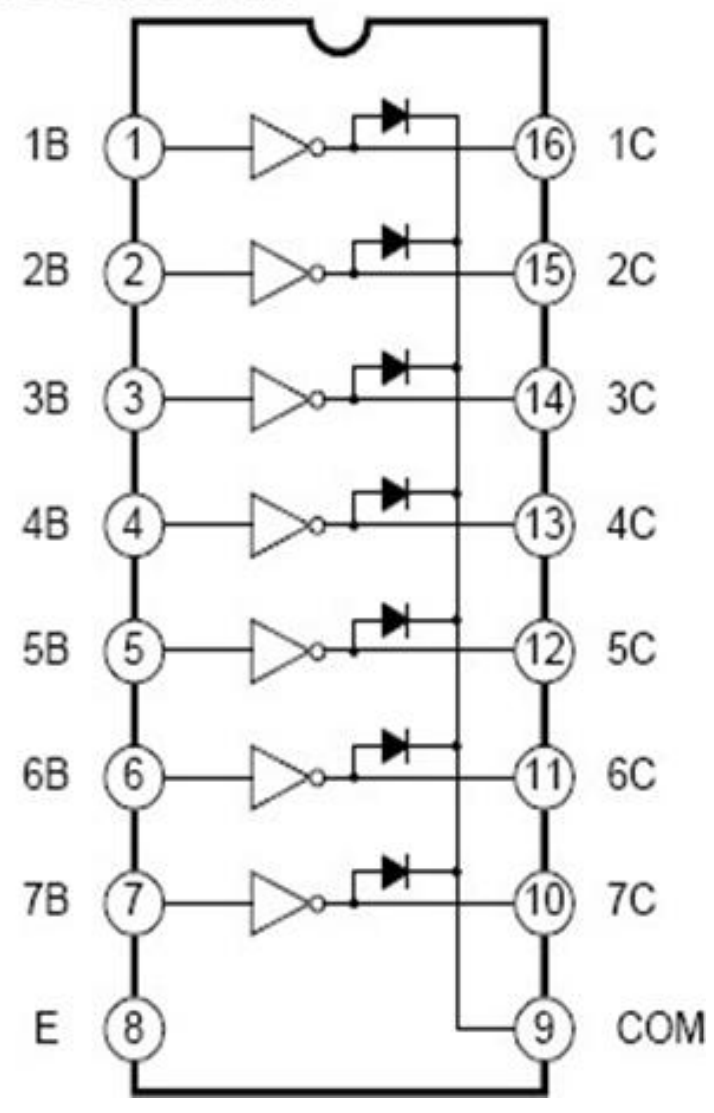

Figure 4.3: shows the relay derive IC LED:-

LEDs are semiconductor devices are made out of silicon. When current passes through the LED, it emits photons as a byproduct. Normal light bulbs produce light by heating a metal filament until its white hot. LEDs present many advantages over traditional light sources including lower energy consumption, longer lifetime, improved robustness, smaller size and faster switching. They do dozens of different jobs and are found in all kinds of devices. 
Among other things, they form numbers on digital clocks, transmit information from remote controls, light up watches and tell you when your appliances are turned on. Collected together, they can form images on a jumbo television screen or illuminate a traffic light..

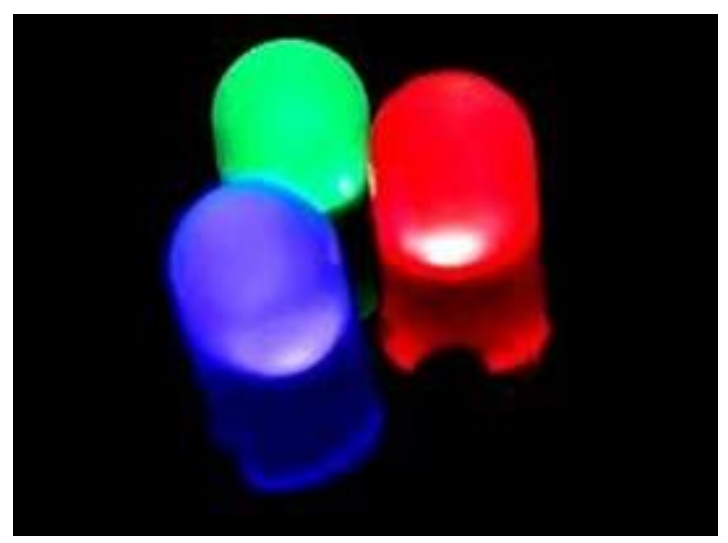

Figure 4.4: shows actual LEDs

\section{RESULT}

This Project aimed at introduced a standard procedure for the design of large-scale institutional gridconnected solar PV systems. The standard procedure was validated in the design of a grid-connected solar PV system by using controller PV systems with battery back-up (sometimes referred to as uninterrupted power supply) are becoming most popular. With solar customers in many states now receiving a low price for electricity sold back to the grid, battery back-up systems can be a viable alternative as they use the electricity stored during the day to run your house at night. A solar PV based scheme for application in rural areas is proposed in this project it is realized by involving a new concept followed by relay inverter. Performances of the management in real conditions the management developed helps integration of PV power into the grid as peak loads are shaved. Depending of the reactive management in real conditions, the power fluctuation of the PV production is balanced to the power exchanged with the grid or with the battery. The System developed Depends of the reactive management in real conditions, the power fluctuation of the PV production is balanced to the power interchanged with the grid or with the batteries.

\section{CONCLUSION}

This project intended to design an auto power control of four different sources circuit, the main scope of this paper is to provide a continuous power supply to the load through any of the sources in the absence of any source. Taking in consideration the use of the source whose cost is the lowest then, the higher and so on.

The first stage was to provide the four different sources, as it's not practicable to do so at the moment we connected four lines to a particular load which is a $220-\mathrm{V}$ lamp each line connected to a $5-\mathrm{V}$ relay representing the four sources. The second stage was to control the circuit with the aid of ATMEGA-32 microcontroller by burning a $\mathrm{C}$ language program into the ATMEGA-32.

To sum up, the objectives which were stated in the first chapter were met successfully. The significance of this paper lies in its various advantages and wide places of applications where this project can be used efficiently.

\section{REFERENCES}

[1]. Auto power control to four different sources, by/ Smt. Thilagavathy R1, Smt. Spoorthi Y2, Ms. Nalina H D3 1,2,3 Assistant Professor, Dept. of ECE, GSSSIETW, Mysuru, Karnataka, (India), NOVEMBER 2016.

[2]. El-Ali, A., N. Moubayed, and R. Outbib. "Comparison between solar and wind energy in Lebanon." Electrical Power Quality and Utilization, 2007. EPQU 2007. 9th International Conference on. IEEE, 2007.

[3]. Difference between Wind Power and Solar Power $\quad$ web site: http://www.differencebetween.net/science/phy sics-science/difference-between-wind-powerandsolar-power/. 
[4]. Solar Energy in India UNDP in India| web site: http://www.sd.undp.org/content/india/en/home /ourwork/environmentandenergy/success stories/Solar_Energy_in_India.htm/.

[5]. Lahmeyer International: Wind Energy: Development of Three Wind Farms in India| web site: http://www.lahmeyer.de/projekte/energie/wind energie/single/article/wind developmentof-three-wind-farms-inindia.html.

[6]. Robert Douwona - Owoo Design and construction of three phase automatic transfer switch. A thesis presented at regent university college of science and technology Ghana, 2000.

[7]. Solar Energy in India UNDP in India| web site: http://www.sd.undp.org/content/india/en/home /ourwork/environmentandenergy/success stories/Solar_Energy_in_India.html.

[8]. LS Ezema, B U Peter, O O Harris, "DESIGN OF AUTOMATIC CHANGE OVER SWITCH WITH GENERATOR CONTROL MECHANISM", ISSN: 2223-9944, vol 3, No 3, November 2003.

[9]. Jonathan (2007) - Manually Controlled Changeover System. Vol.2, No.5. November, 2011.

[10]. Mbaocha C. Smart Phase Changeover Switch using AT89C52 Microcontroller. Journal of Electrical and Electronics Engineering vol.1; Issue 3: PP 31-44, 2012.

[11]. Katz R and Boriella G Contemporary Logic Design. 2nd edition. Prentice Hall, Italy. PP 445-589, 2005.

[12]. ULN2003A - Wikipedia web site:https://en.wikipedia.org/wiki/ULN2003A.H ow Light Emitting Diodes Work | How Stuff Work web site: http://electronics.howstuffworks.com/led.htm.

[13]. Interfacing 16x2 LCD with Atmega32 Microcontroller using Atmel Studio| web site: https://www.electrosome.com/interfacing-lcdatmega32-microcontroller-atmel-studio/.

\section{Cite this article as :}

Prof. Najma Siddiqui, Mohammad Anwar, Junaid Akhtar, Ehtesham Asif, Mohammad Rehan, Tafim Khan, " Design And Implementation of Solar Panel MPPT With Inverter And Battery Towards Load Side", International Journal of Scientific Research in Science and Technology(IJSRST), Print ISSN : 23956011, Online ISSN : 2395-602X, Volume 8, Issue 3, pp.943-951, May-June-2021. Available at doi : https://doi.org/10.32628/IJSRST12183205 Journal URL : https://ijsrst.com/IJSRST12183205 